\title{
MicroRNA-550a-3-5p controls the brain metastasis of lung cancer by directly targeting YAP1
}

Liang Wei ${ }^{1 \dagger}$, Guangxue Wang ${ }^{2 \dagger}$, Cheng Yang ${ }^{1}$, Yanfei Zhang ${ }^{1}$, Yiming Chen ${ }^{1}$, Chunlong Zhong ${ }^{1 *}$ and Qinchuan $\mathrm{Li}^{2,3 *}$ (1)

\begin{abstract}
Background: This study aimed to explore the potential regulatory mechanisms of brain metastasis and to identify novel underlying targets of lung cancer with brain metastasis.

Methods: Exosomes were isolated from the plasma of lung cancer patients with or without brain metastasis and low or high metastatic lung cancer cells, and small RNA from plasma-derived exosomes were sequenced. Differentially expressed miRNAs (DE-miRNAs) were identified. Human brain microvascular endothelial cells (HBMECs) were transfected with miR-550a-3-5p mimics or inhibitors and exosomes. Cell viability, migration, and apoptosis/cycle were determined using Cell Counting Kit-8 (CCK-8), Transwell, and flow cytometry, respectively. Western blotting was used to measure the expression of the associated proteins. Finally, a dual-luciferase reporter gene assay was performed to confirm the miR-550a-3-5p target.

Results: Transmission electron microscopy, NanoSight, and western blotting showed that exosomes were successfully isolated and cell-derived exosomes could be taken up by HBMECs. Sequencing identified 22 DE-miRNAs which were enriched in the MAPK, chemokine, PPAR, and Wnt signaling pathways. MiR-550a-3-5p was significantly enriched in brain metastatic exosomes. Cellular experiments showed that miR-550a-3-5p and exosome enrichment signifcantly inhibited cell viability and migration, promoted apoptosis, and regulated the cell cycle of HBMECs compared with the controls $(P<0.05)$. Compared with the controls, high levels of both miR-550a-3-5p and exosomes markedly upregulated cleaved-PARP expression, but downregulated the expression of pRB, CDK6, YAP1, CTGF, and CYR61 ( $P<$ 0.05). Finally, YAP1 was confirmed to bind directly to miR-550a-3-5p.
\end{abstract}

Conclusion: Our results indicate that miR-550a-3-5p and YAP1 may be novel potential targets for controlling brain metastasis.

Keywords: Lung cancer, Brain metastasis, HBMECs, miR-550a-3-5p, YAP1

*Correspondence: drchunlongzhong@tongji.edu.cn; qinchuanli@tongji.edu.cn

'Liang Wei and Guangxue Wang are co-first authors

${ }^{1}$ Department of Neurosurgery, East Hospital, Tongji University School

of Medicine, 150 Jimo Road, Shanghai 200120, China

${ }^{2}$ Research Center for Translational Medicine, East Hospital, Tongji

University School of Medicine, 150 Jimo Road, Shanghai 200120, China

Full list of author information is available at the end of the article

\section{Background}

Lung cancer is the leading cause of cancer deaths worldwide, and can induce local and systemic immunosuppression and promote tumor growth and metastasis [1]. Brain metastasis is an important cause of morbidity and mortality in lung cancer patients [2]. At initial diagnosis, $10-15 \%$ of lung cancer patients are also diagnosed with brain metastasis and approximately $40 \%$ develop 
brain metastasis during their illness [3-5]. Treatment for patients diagnosed with early stage lung cancer usually involves surgical resection with occasional adjuvant radiotherapy or chemotherapy [6]. However, once patients develop lung cancer with brain metastasis, radical treatment becomes almost impossible, and the focus shifts to life-prolonging treatments, primarily systemic chemotherapy $[1,7]$. Even after multimodal therapy, the survival of lung cancer patients with brain metastasis remains low, limited to weeks or months [4]. To date, the molecular mechanisms that can inhibit the progression of lung cancer metastases have not been identified, thus there is an urgent need to identify new targets for the prevention and control of brain metastasis of lung cancer.

Exosomes are membrane vesicles approximately $30-300 \mathrm{~nm}$ in diameter that are secreted by almost all cells [8]. Exosomes act as tools for cell-to-cell communication and contain RNAs, proteins, lipids, and other bioactive molecules, and are receiving increasing attention [9]. Studies have shown that the contents of cancerderived exosomes can be transferred to other types of cells and pre-metastatic niches to regulate cell function and promote tumor progression [10-12]. Ham et al. [13] showed that breast cancer-associated exosomes induced the secretion of interleukin (IL)- 6 and a survival promoting phenotype in macrophages through the glycoprotein 130-STAT3 signaling pathway. Additionally, an increasing body of evidence indicates that exosomal microRNAs (miRNAs) are involved in metastasis and can serve as potential targets in the treatment of brain metastasis [14, 15]. MiRNAs, a subgroup of non-coding RNAs that are approximately 22 nucleotides long, have been reported to participate in a variety of physiological and pathological processes such as cell proliferation, migration, apoptosis, invasion, and angiogenesis by regulating their target genes [16, 17]. A study by Zeng et al. [18] demonstrated that miR-25-3p (an miRNA that promotes colorectal cancer metastasis) was transferred to endothelial cells by colorectal cancer-derived exosomes and facilitated the formation of pre-metastatic niches by inducing vascular permeability and angiogenesis. Another study showed that breast cancer-associated fibroblast-derived exosomes significantly promoted tumor progression and damaged the function of tumors by infiltrating immune cells via the miR-92/PD-L1 pathway [19]. However, few key miRNAs that link lung cancer with brain metastasis have been reported, and their potential mechanisms in brain metastasis remain unknown.

Therefore, our study sequenced RNA from exosomes isolated from the plasma of lung cancer patients with or without brain metastasis and identified differentially expressed miRNAs (DE-miRNAs). miR-550a-3-5p was significantly upregulated in exosomes isolated from the plasma of lung cancer patients with brain metastasis, and was selected for further cell mechanism studies. Our findings improve understanding of the occurrence and progression of brain metastases in lung cancer patients and identified new potential therapeutic targets and pathways underlying brain metastasis.

\section{Methods \\ Collection of clinical samples and isolation of exosomes from plasma}

This study was approved by the Human Biomedical Research Ethics committee of Shanghai East Hospital affiliated to Tongji University [(2020) Research on No.135], and informed consent was obtained from all participants. Lung cancer patients with brain metastasis $(\mathrm{n}=3)$ and lung cancer patients without brain metastasis $(\mathrm{n}=3)$ were recruited from Shanghai East Hospital affiliated with Tongji University, and a $10 \mathrm{~mL}$ blood sample was collected from each patient. Next, exosomes were isolated from the plasma at $4{ }^{\circ} \mathrm{C}$. Five millilitre plasma was then centrifuged at $12,000 \times g$ for $30 \mathrm{~min}$ and the supernatant transferred to a new tube. After filtration through a $0.22 \mu \mathrm{m}$ sterile filter, the supernatant was centrifuged at $1,20,000 \times g$ for $60 \mathrm{~min}$. The pellet was resuspended in pre-cooled PBS and transferred to a clean ultra-high-speed centrifuge tube. After centrifugation at $1,20,000 \times g$ for $60 \mathrm{~min}$, the pellet was resuspended in $200 \mu \mathrm{L}$ pre-cooled PBS and stored at $-80{ }^{\circ} \mathrm{C}$.

\section{Cell culture and isolation of exosomes from 95C and 95D cell lines}

Human low metastatic lung cancer cell line 95C, human high metastatic lung cancer cell line 95D, and human brain microvascular endothelial cells (HBMECs) were purchased from Cell Bank, Chinese Academy of Sciences (Shanghai, China). 95C and 95D cell lines were cultured in Dulbecco's modified Eagle's medium (DMEM; Gibco, Grand Island, NY, USA) containing $10 \%$ fetal calf serum (FBS, Gibco) and $1 \%$ penicillin/streptomycin (Gibco) and incubated at $37{ }^{\circ} \mathrm{C}$ in an incubator with $5 \% \mathrm{CO}_{2}$. HBMECs were maintained in F12K medium (Gibco) with $10 \% \mathrm{FBS}$ and $1 \%$ penicillin/streptomycin and then cultured at $37{ }^{\circ} \mathrm{C}$ in an incubator with $5 \% \mathrm{CO}_{2}$. The cells were passaged once they reached $80-90 \%$ confluence.

Exosomes were extracted from the 95C and 95D cells at $4{ }^{\circ} \mathrm{C}$. Briefly, the $95 \mathrm{C}$ and $95 \mathrm{D}$ cells were harvested and washed with PBS. The cells were cultured for $48 \mathrm{~h}$ in serum-free medium and then transferred to a $50 \mathrm{~mL}$ tube and centrifuged at $5000 \times g$ for $5 \mathrm{~min}$. The supernatant was collected and centrifuged again at $2000 \times g$ for $30 \mathrm{~min}$, and the supernatant collected. Next, an equal volume of pre-cooled 16\% PEG 6000 was added to, and thoroughly mixed, with the supernatant. After 
overnight incubation at $4{ }^{\circ} \mathrm{C}$, the mixture was centrifuged at $10,000 \times g$ for $60 \mathrm{~min}$, the pellet collected and resuspended in $1 \mathrm{~mL}$ PBS. After centrifuged at $1,00,000 \times g$ for $70 \mathrm{~min}$, the pellet was resuspended in $200 \mu \mathrm{L}$ PBS and stored at $-80{ }^{\circ} \mathrm{C}$ until use.

\section{Identification of exosomes}

The concentration of isolated exosomes was determined using a BCA assay kit (BOSTER Biological Technology Co., Ltd., CA, USA), following the manufacturer's instructions. Thereafter, a transmission electron microscope (TEM, JEOL LTD, Peabody, MA, USA) was used to visualize the morphology of exosomes, as previously described [20]. Following the protocols described by Soares et al. [21], particle exosome sizes were measured using a NanoSight NS300 particle size analyzer (NTA, Malvern Panalytical, Malvern, UK). Western blotting was used to determine the expression of exosome-specific protein markers, including CD9, CD63, and HSP70 [22].

\section{Small RNA sequencing of plasma-derived exosomes}

The plasma-derived exosomes were sent to Yanzai Biotechnology (Shanghai) Co., Ltd., (Shanghai, China) for small RNA sequencing. The Expdiff method was used to identify differentially expressed miRNAs (DE-miRNAs) between lung cancer patients with brain metastasis and lung cancer patients without brain metastasis. The thresholds for screening DE-miRNAs were |log2Fold change $(\mathrm{FC}) \mid>1$ and $\mathrm{P}<0.05$. Targetscan, miRanda, and PITA software were used to predict the target genes of the DE-miRNAs [23]. These DE-miRNAs were then submitted for Gene Ontology (GO) and Kyoto Encyclopedia of Genes and Genomes (KEGG) pathway analyses.
Enriched GO terms and KEGG pathways with $\mathrm{P}<0.05$ were identified.

\section{Quantitative reverse transcription PCR (RT-qPCR)}

We selected five DE-miRNAs (three upregulated and two downregulated) for further validation. Total RNA was isolated from plasma-derived exosomes using RNAiso Plus kit (Trizol, Takara Biomedical Technology Co., Ltd., Beijing, China) and twice the volume of isopropanol, following the manufacturer's recommendations. The levels of miRNAs in the exosomes were determined using the stem ring method [24]. Briefly, total RNA was reverse transcribed into cDNA using the PrimeScript ${ }^{\mathrm{TM}}$ II 1 st Strand cDNA synthesis Kit (Takara Biomedical Technology Co., Ltd.). First, $20 \mu \mathrm{L}$ denaturing reaction solution, including $3 \mu \mathrm{L}$ RT primer $(10 \mu \mathrm{M})$, dNTP mixture (10 nM), RNA template $(10 \mu \mathrm{L})$, and RNase free $\mathrm{dH}_{2} \mathrm{O}$ $(6 \mu \mathrm{L})$, was prepared and used for miRNA reverse transcription. The total volume for miRNA reverse transcription was $20 \mu \mathrm{L}$ and included $14 \mu \mathrm{L}$ denaturing reaction solution, $4 \mu \mathrm{L}$ of $5 \times$ PrimeScript II buffer, $0.5 \mu \mathrm{L}$ RNase inhibitor $(40 \mathrm{U} / \mu \mathrm{L}), 1 \mu \mathrm{L}$ PrimeScript II RTase (200 U/ $\mu \mathrm{L}$ ), and $0.5 \mu \mathrm{L}$ RNase free $\mathrm{dH}_{2} \mathrm{O}$. miRNA reverse transcription was conducted at $42{ }^{\circ} \mathrm{C}$ for $60 \mathrm{~min}$, followed by $95^{\circ} \mathrm{C}$ for $5 \mathrm{~min}$. Reverse transcriptase was used for qPCR. The total volume of qPCR was $20 \mu \mathrm{L}$ and included $10 \mu \mathrm{L}$ SYBR Premix EX Taq, $1 \mu \mathrm{L}$ forward primer $(10 \mu \mathrm{M}), 1 \mu \mathrm{L}$ reverse primer $(10 \mu \mathrm{M}), 2 \mu \mathrm{L}$ cDNA, and $6 \mu \mathrm{L}$ RNase free water. The RT-qPCR reaction was initiated at $50{ }^{\circ} \mathrm{C}$ for $2 \mathrm{~min}$, followed by 40 cycles of $95^{\circ} \mathrm{C}$ for $2 \mathrm{~min}, 95^{\circ} \mathrm{C}$ for $15 \mathrm{~s}$, and $60{ }^{\circ} \mathrm{C}$ for $60 \mathrm{~s}$. The sequences of all primers are listed in Table 1. U6 served as a housekeeping gene, and the levels of miR-550a-3-5p, miR-1226-3p, miR-144-3p,

Table 1 The sequences of all primers

\begin{tabular}{|c|c|}
\hline Primer & Sequence $\left(5^{\prime}-3^{\prime}\right)$ \\
\hline \multirow[t]{2}{*}{ has-miR-550a-3-5p } & JH:GTCGTATCCAGTGCAGGGTCCGAGGTATTCGCACTGGATACGACCTCTTA \\
\hline & F: GCGCAGTGCCTGAGGGAG \\
\hline \multirow[t]{2}{*}{ hsa-miR-1226-3p } & JH:GTCGTATCCAGTGCAGGGTCCGAGGTATTCGCACTGGATACGACCTAGGG \\
\hline & F: GCCTCACCAGCCCTGTGTT \\
\hline \multirow[t]{2}{*}{ hsa-miR-3200-5p } & JH:GTCGTATCCAGTGCAGGGTCCGAGGTATTCGCACTGGATACGACACCTTG \\
\hline & F: GCGCAATCTGAGAAGGCGCA \\
\hline \multirow[t]{2}{*}{ hsa-miR-144-3p } & JH:GTCGTATCCAGTGCAGGGTCCGAGGTATTCGCACTGGATACGACAGTACA \\
\hline & F: GCGCGCGCTACAGTATAGATGA \\
\hline \multirow[t]{2}{*}{ hsa-miR-27a-3p } & JH:GTCGTATCCAGTGCAGGGTCCGAGGTATTCGCACTGGATACGAC GCGGAA \\
\hline & F: GCGCGTTCACAGTGGCTAAG \\
\hline Downstream universal primer & R: GTGCAGGGTCCGAGGT \\
\hline \multirow[t]{3}{*}{ U6 } & RT:GTCGTATCCAGTGCAGGGTCCGAGGTATTCGCACTGGATACGACAAAATATG \\
\hline & F: CTCGCTTCGGCAGCACA \\
\hline & R: AACGCTTCACGAATTTGCGT \\
\hline
\end{tabular}


miR-27a-3p, and miR-3200-5p in exosomes were calculated using the $2^{-\Delta \Delta \mathrm{Ct}}$ method [25].

Cellular uptake of cancer cell-derived exosomes in HBMECs Lung cancer cell-derived exosomes were labeled with PKH67 (green fluorescent cell linker for general cell membrane labeling) using a commercial kit (PKH67GL1KT; Sigma-Aldrich, USA) following the manufacturer's instructions. Briefly, $700 \mu \mathrm{L}$ lung cancer cell-derived exosomes and $1300 \mu \mathrm{L}$ Diluent $\mathrm{C}$ were mixed, and then $16 \mu \mathrm{L}$ PKH67 dye and $2 \mathrm{~mL}$ Diluent $\mathrm{C}$ were added. The mixture was incubated at room temperature for $5 \mathrm{~min}$ and $4 \mathrm{~mL}$ of $1 \%$ BSA was added to bind excess dye. After centrifugation at $1,20,000 \times g$ for $90 \mathrm{~min}$ at $4{ }^{\circ} \mathrm{C}$, the pellet (PKH67-labeled exosomes) was resuspended in $300 \mu \mathrm{L}$ PBS.

HBMECs were seeded in a 24-well plate and cultured overnight. Next, $10 \mu \mathrm{L}$ PKH67-labeled exosomes were added to the cells. After culturing for $24 \mathrm{~h}$ and $48 \mathrm{~h}$, the medium was removed and the cells washed with PBS. The HBMECs were then fixed with 4\% paraformaldehyde at room temperature for $20 \mathrm{~min}$. After washing, $0.1 \%$ TritonX-100 was added and the cells cultured for $20 \mathrm{~min}$. After washing, 3\% BSA was added and the mixture incubated for $1 \mathrm{~h}$ to block non-specific binding. After washing, mounting medium with DAPI was added to stain the cells and a laser scanning confocal microscope (TCS SP8, Leica Microsystems, Inc., USA) was used to observe the cells at $400 \times$ magnification.

\section{Cell transfection}

Cell transfection was carried out using the methods described by Wan et al. [26]. Briefly, HBMECs were seeded in a 24-well plate and cultured overnight. After the cells had grown to a density of $70 \%$, the cells were transfected with $50 \mathrm{nM}$ miR-550a-3-5p mimics, miR550a-3-5p inhibitor, and miRNA negative control (NC) using Lipofectamine 2000 (Thermo Fisher Scientific), according to the manufacturer's protocols. miR-550a3-5p mimics, miR-550a-3-5p inhibitor, and miRNA NC were designed and provided by Yanzai Biotechnology Co., Ltd., (Shanghai, China). After $6 \mathrm{~h}$ of transfection, the medium was replaced with complete medium containing $10 \%$ FBS. After culturing for another $48 \mathrm{~h}$, total RNA was extracted from the cells with different treatments, and the level of miR-550a-3-5p was measured using RT-qPCR to evaluate the cell transfection efficiency. The miR-550a3-5p sequences are shown in Table 1.

\section{Cell viability and migration assays}

HBMECs were seeded in a 96-well plate and divided into five groups: control, miRNA NC, miR-550a-3-5p mimics, miR-550a-3-5p inhibitor, and exosomes. The cells in the miRNA NC, miR-550a-3-5p mimics, miR550a-3-5p inhibitor, and exosomes were transfected with miRNA NC, miR-550a-3-5p mimics, miR-550a3-5p inhibitor, and high metastatic lung cancer cellderived exosomes (final concentration of $10 \mu \mathrm{g} / \mathrm{mL}$ ), respectively. The cells in the control group were treated with an equal volume of PBS. After culturing for $24 \mathrm{~h}$, $48 \mathrm{~h}, 72 \mathrm{~h}$ or $96 \mathrm{~h}, 10 \mu \mathrm{L}$ of cell counting kit- 8 (CCK8, Beyotime Biotechnology) was added to the cells and cultured for a further $2 \mathrm{~h}$, The optical density was measured at $450 \mathrm{~nm}$ using a microplate reader (Thermo Fisher Scientific).

Migration of HBMECs was assessed using Transwell chambers (pore size $8 \mu \mathrm{m}$; Guangzhou Jet Bio-Filtration Co., Ltd., Guangzhou, China). After the different treatments, HBMECs were harvested and resuspended in serum-free medium to adjust the cell density to $3 \times$ $10^{5}$ cells $/ \mathrm{mL}$. Thereafter, $0.2 \mathrm{~mL}$ cell suspensions were inoculated into the upper chamber of Transwell chambers and complete medium containing 10\% FBS was added into the lower chamber. After culturing for $24 \mathrm{~h}$, the Transwell chambers were removed and washed twice with PBS. The cells were fixed with $4 \%$ paraformaldehyde for $10 \mathrm{~min}$, washed twice with PBS, stained with $0.5 \%$ crystal violet (Beyotime Biotechnology), and then incubated at room temperature for $10 \mathrm{~min}$. After washing, the cells were observed and photographed under a microscope.

\section{Cell apoptosis and cycle assays}

The apoptosis of HBMECs subjected to different treatments was determined using an Annexin V-FITC/PI apoptosis assay kit, according to the manufacturer's protocol. Briefly, cells subjected to different treatments were collected and resuspended in $100 \mu \mathrm{L}$ of $1 \times$ binding buffer. Subsequently, $5 \mu \mathrm{L}$ FITC-Annexin V and $5 \mu \mathrm{L}$ PI $(50 \mu \mathrm{g} / \mathrm{mL})$ were added and the mixture incubated in the dark at $25^{\circ} \mathrm{C}$ for $15 \mathrm{~min}$. Finally, $400 \mu \mathrm{L}$ of $1 \times$ binding buffer was added and cell images acquired using flow cytometry.

The cell cycle was also detected using flow cytometry. Cells in each treatment group were centrifuged at $1000 \mathrm{rpm}$ for $5 \mathrm{~min}$ and resuspended in $0.5 \mathrm{~mL}$ PBS. Next, $5 \mathrm{~mL}$ of $70 \%$ pre-cooled ethyl alcohol was added to the cells and the mixture incubated overnight at $4{ }^{\circ} \mathrm{C}$. The next day, the cells were centrifuged at $1500 \mathrm{rpm}$ for $6 \mathrm{~min}$ and washed with $6 \mathrm{~mL}$ PBS. After centrifugation at $1000 \mathrm{rpm}$ for $6 \mathrm{~min}$, the pellet was resuspended in $0.3 \mathrm{~mL}$ PBS and transferred to a new tube. RNase A was added and after incubation at $37{ }^{\circ} \mathrm{C}$ for $30 \mathrm{~min}, 5 \mu \mathrm{L}$ PI was added. After staining in the dark at $4{ }^{\circ} \mathrm{C}$ for 15 min, a flow cytometer was used to determine the cell cycle. 


\section{Western blot assays}

Total protein was isolated from cells subjected to different treatments using RIPA lysis buffer (Beyotime Biotechnology) and the concentrations of total protein were determined using a BCA assay kit (BOSTER Biological Technology Co., Ltd.). Protein samples $(20 \mu \mathrm{g})$ were separated using 10\% SDS-PAGE and then transferred to PVDF membranes. After blocking with 5\% skim milk, the membranes were incubated with anti-cleaved-Poly(ADP-ribose) polymerase (PARP) antibody (1:1000, Abcam), anti-RB transcriptional corepressor 1 (pRB) antibody (1:1000, Abcam), anti-cyclin dependent kinase 6 (CDK6) antibody (1:1000, Abcam), anti-Yes1 associated transcriptional regulator (YAP1) antibody (1:1000, Abcam), anti- connective tissue growth factor (CTGF) antibody (1:1000, Proteintech Group, Inc.), anti-cysteine rich angiogenic inducer 61 (CYR61) antibody (1:1000, Abcam), and anti-GAPDH antibody (1:10,000, Proteintech Group, Inc.) overnight at $4{ }^{\circ} \mathrm{C}$. After washing three times with PBST (PBS with 0.05\% Tween20), the membranes were incubated with the secondary antibody (1: 5000, Jackson ImmunoResearch) at $37{ }^{\circ} \mathrm{C}$ for $2 \mathrm{~h}$. After five washes with PBST, the protein bands were visualized using a Millipore ECL system (Shanghai Tanon Technology Co. Ltd., Shanghai, China).

\section{Dual-luciferase reporter gene assay}

Choe et al. [27] previously showed that YAP1 is the target gene of miR-550a-3-5p in human colon cancer cells (HCT116). A dual-luciferase reporter gene assay was carried out to further verify the conclusion in the lung cancer cell-derived exosomes. The sequence of the YAP1 3 '-untranslated region ( $3^{\prime}$-UTR) was designed and provided by Yanzai Biotechnology Co., Ltd., (Shanghai, China) and the pGL3-basic plasmid was used to construct the YAP1 3'-UTR reporter plasmid (pGL3-YAP1). $293 \mathrm{~T}$ cells were then seeded in a 96-well plate at a density of 4 $\times 10^{4}$ cells/well and cultured overnight. The next day, the medium was changed to serum-free medium, and $0.4 \mu \mathrm{g}$ pGL3-basic plasmid or $0.4 \mu \mathrm{g}$ pGL3-YAP1 were cotransfected into $293 \mathrm{~T}$ cells with $100 \mathrm{nM}$ miR-550a-3-5p mimics or $100 \mathrm{nM}$ NC mimics using Lipofectamine 3000 (Thermo Fisher Scientific, Waltham, MA, USA) following the manufacturer's instructions. After $6 \mathrm{~h}$ of transfection, the cell medium was replaced with complete medium. After culturing for another $48 \mathrm{~h}$, the cell supernatant was removed and $150 \mu \mathrm{L}$ of lysis buffer from the dal-luciferase reporter gene assay kit (Beyotime Biotechnology) was added. After centrifugation at $12,000 \times g$ for $5 \mathrm{~min}$, the supernatant was used to determine the relative light unit using a dal-luciferase reporter gene assay kit following the manufacturer's recommendations.

\section{Statistical analysis}

Graphpad prism 5 (Graphpad Software, San Diego, CA) was used for statistical analyses. Data are expressed as mean \pm standard deviation (SD). For comparison between two groups, student's t test was performed, whereas one-way analysis of variance (ANOVA) followed by Bonferroni method was used to compare significant differences among more than two groups. $P<0.05$ was considered statistically significant.

\section{Results}

Characterization of plasma-derived exosomes and lung cancer cell-derived exosomes

Exosomes were extracted from the plasma of lung cancer patients with or without brain metastasis and high or low metastatic lung cancer cells, and characterized using NTA, TEM, and western blotting. TEM results showed that the exosomes were cup-shaped or nearly round and approximately $100 \mathrm{~nm}$ in diameter (Fig. 1A). NTA results showed that the major peaks of substances isolated from the plasma of lung cancer patients with or without brain metastasis and high or low metastatic lung cancer cells were approximately $94 \mathrm{~nm}$ or $90 \mathrm{~nm}$ and $95 \mathrm{~nm}$ or $99 \mathrm{~nm}$, respectively (Fig. 1B). These results are in agreement with the size distribution of exosomes, as previously reported [28]. Finally, western blotting showed that CD9, CD63, and HSP70, which are exosome markers, were all expressed in the exosomes, while calnexin was not (Fig. 1C). These results indicate that exosomes were successfully isolated from the plasma and cells.

\section{Small RNA sequence analyses and RT-qPCR validation}

Exosomes isolated from the plasma of lung cancer patients with or without brain metastasis were sequenced. A total of 22 DE-miRNAs, including 10 upregulated and 12 downregulated miRNAs, were identified based on the criteria: $\left|\log _{2} \mathrm{FC}\right|>1$ and $\mathrm{P}<0.05$, (Fig. 2A). A heatmap representing the cluster analysis of these DE-miRNAs is shown in Fig. 2B. A total of 21,759 mRNA targets of these DE-miRNAs were predicted using TargetScan, miRanda, and PITA software (Fig. 2C). The DE-miRNAs were then subjected to GO term and KEGG pathway analyses. A total of 44 biological processes (BP), 9 cellular components $(\mathrm{CC})$, and 13 molecular functions (MF) with $\mathrm{P}<0.05$ were obtained, including anatomical structure development, biological adhesion, biological regulation, and cell communication in BP; cell periphery, extracellular matrix, and plasma membrane in $\mathrm{CC}$; and DNA binding, phosphatase activity, signal transducer activity, and transmembrane transporter activity in MF (Additional file 1: Figure S1A). The DE-miRNAs were significantly enriched in the MAPK signaling pathway, oxytocin signaling pathway, axon guidance, neuroactive 


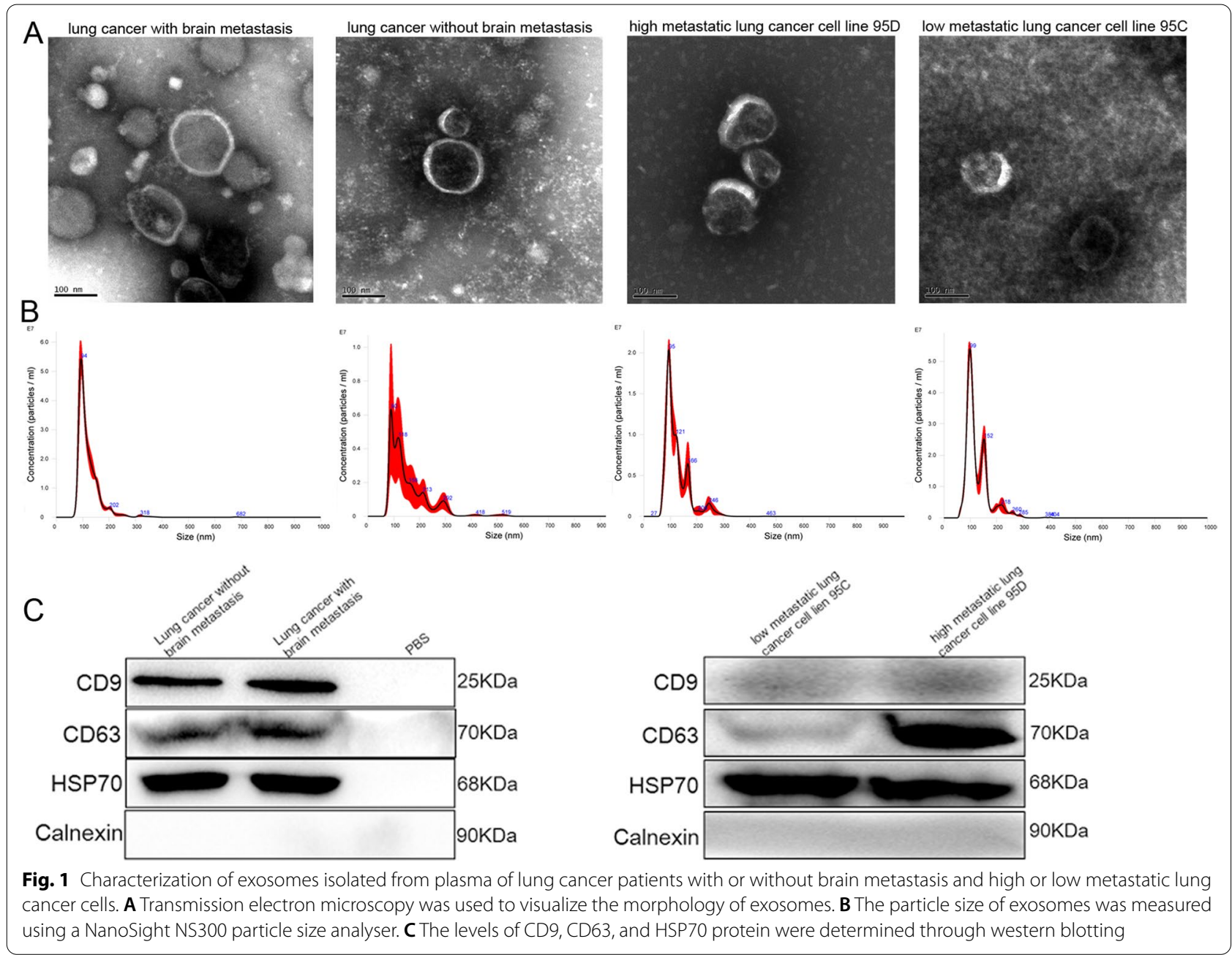

ligand-receptor interaction, calcium signaling pathway, chemokine signaling pathway, PPAR signaling pathway, Wnt signaling pathway, and retinol metabolism (Additional file 1: Figure S1B).

Five DE-miRNAs, including three upregulated miRNAs (hsa-miR-550a-3-5p, hsa-miR-1226-3p, and hsa-miR-3200-5p) and two downregulated miRNAs (hsa-miR-144-3p and hsa-miR-27a-3p), were selected and their levels in the different plasma-derived exosomes determined using RT-qPCR. miR-550a-3-5p levels in the exosomes isolated from lung cancer patients with brain metastasis were significantly higher than those in the exosomes isolated from lung cancer patients without brain metastasis $(P<0.05$, Fig. $3 \mathrm{~A})$. However, the miR-3200-5p levels in the exosomes isolated from lung cancer patients with brain metastasis were opposite to those of miR-550a-3-5p (Fig. 3B). No significant differences in miR-1266-3p levels were observed between exosomes isolated from lung cancer patients with brain metastasis and lung cancer patients without brain metastasis $(P>0.05$; Fig. $3 C)$. The levels of miR-144-3p and miR-27a-3p in the exosomes isolated from lung cancer patients with brain metastasis were clearly decreased compared with those in the exosomes isolated from lung cancer patients without brain metastasis $(P<0.05$; Fig. 3D, E). These results indicate that the consistency rate between RT-qPCR and sequencing was $60 \%$, which implies a relatively high reliability of the sequencing results. Therefore, we selected hsa-miR-550a-3p for subsequent experiments.

\section{Cellular uptake of lung cancer cell-derived exosomes and cell transfection efficiency analysis}

Lung cancer cell-derived exosomes were labeled with green fluorescence through PKH67 staining and HMBECs were stained blue by DAPI. After co-culturing for $24 \mathrm{~h}$ or $48 \mathrm{~h}$, HBMECs took up PKH67-labeled exosomes, and the green fluorescence was stronger after $48 \mathrm{~h}$ of co-culturing compared with $24 \mathrm{~h}$ of coculturing (Fig. 4A). The results indicate that lung cancer 


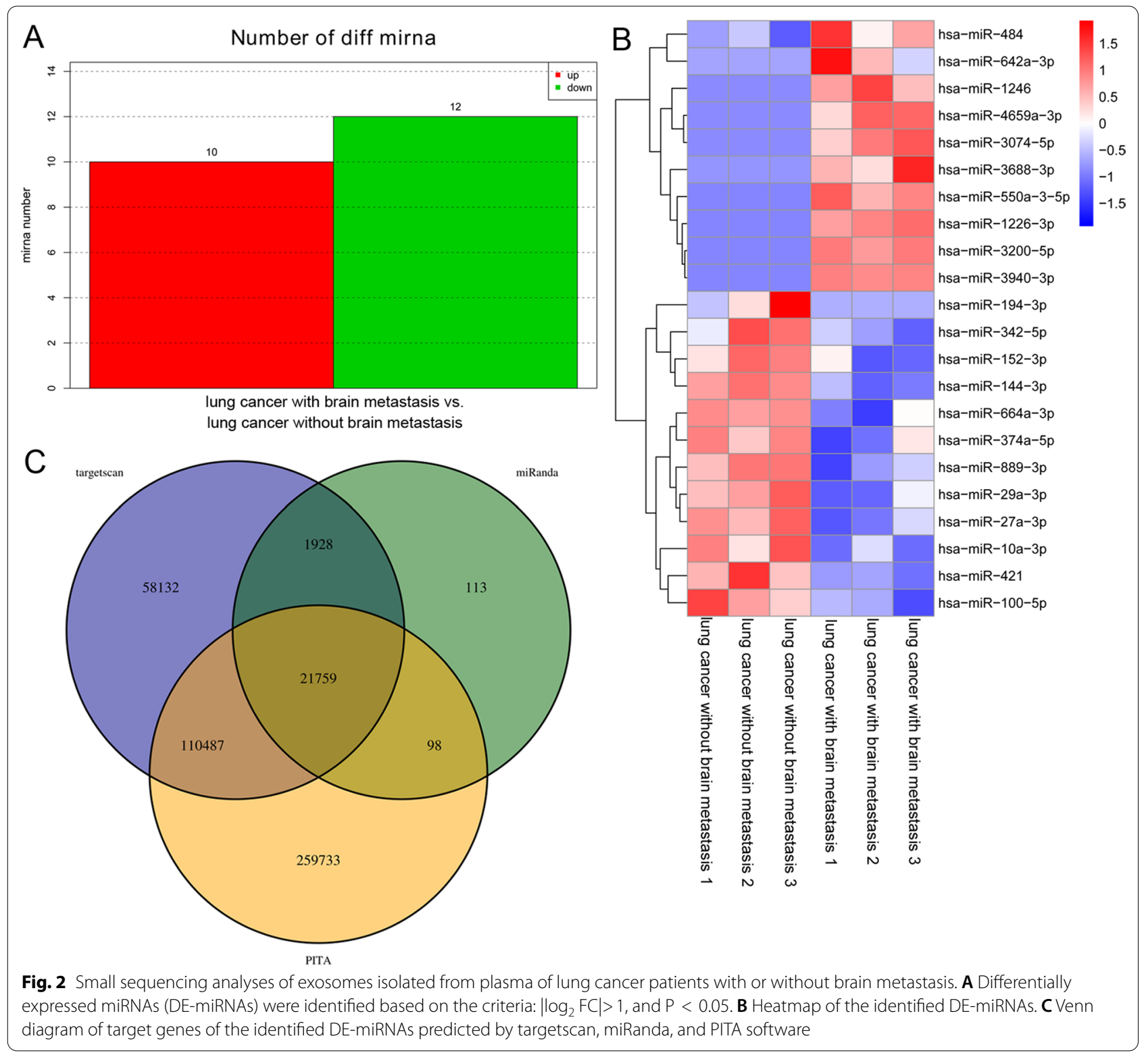

cell-derived exosomes can be taken up by HBMECs, with the fluorescence intensity increasing with the increase in culturing time.

Next, to construct HBMECs with miR-550-3-5p overexpression and knockdown, miR-550a-3-5p mimics and inhibitor were transfected into HBMECs. No significant difference was observed in miR-550a-3-5p levels between the control and miRNA NC groups. Compared with the control group, miR-550a-3-5p levels were significantly decreased in the miR-550a-3-5p inhibitor group $(P<0.05)$ but significantly increased in the miR-550a$3-5$ p mimic group $(P<0.05$; Fig. $4 \mathrm{~B})$. These results indicate that HBMECs with miR-550-3-5p overexpression and knockdown were successfully established and could be used for further experiments.

\section{Cell viability and migration analyses}

The effect of miR-550a-3-5p on the viability of HBMECs was assessed using CCK-8. First, the exosomes isolated from different plasma and cells were treated with HBMECs for $24 \mathrm{~h}, 48 \mathrm{~h}, 72 \mathrm{~h}$, and $96 \mathrm{~h}$. There was no significant difference in cell viability among control, lung cancer without brain metastasis plasma-derived exosomes, and 95C (low metastatic lung cancer cells)derived exosomes (Fig. 5A). After culturing for $24 \mathrm{~h}$, $48 \mathrm{~h}, 72 \mathrm{~h}$, and $96 \mathrm{~h}$, the viability of HBMECs treated 


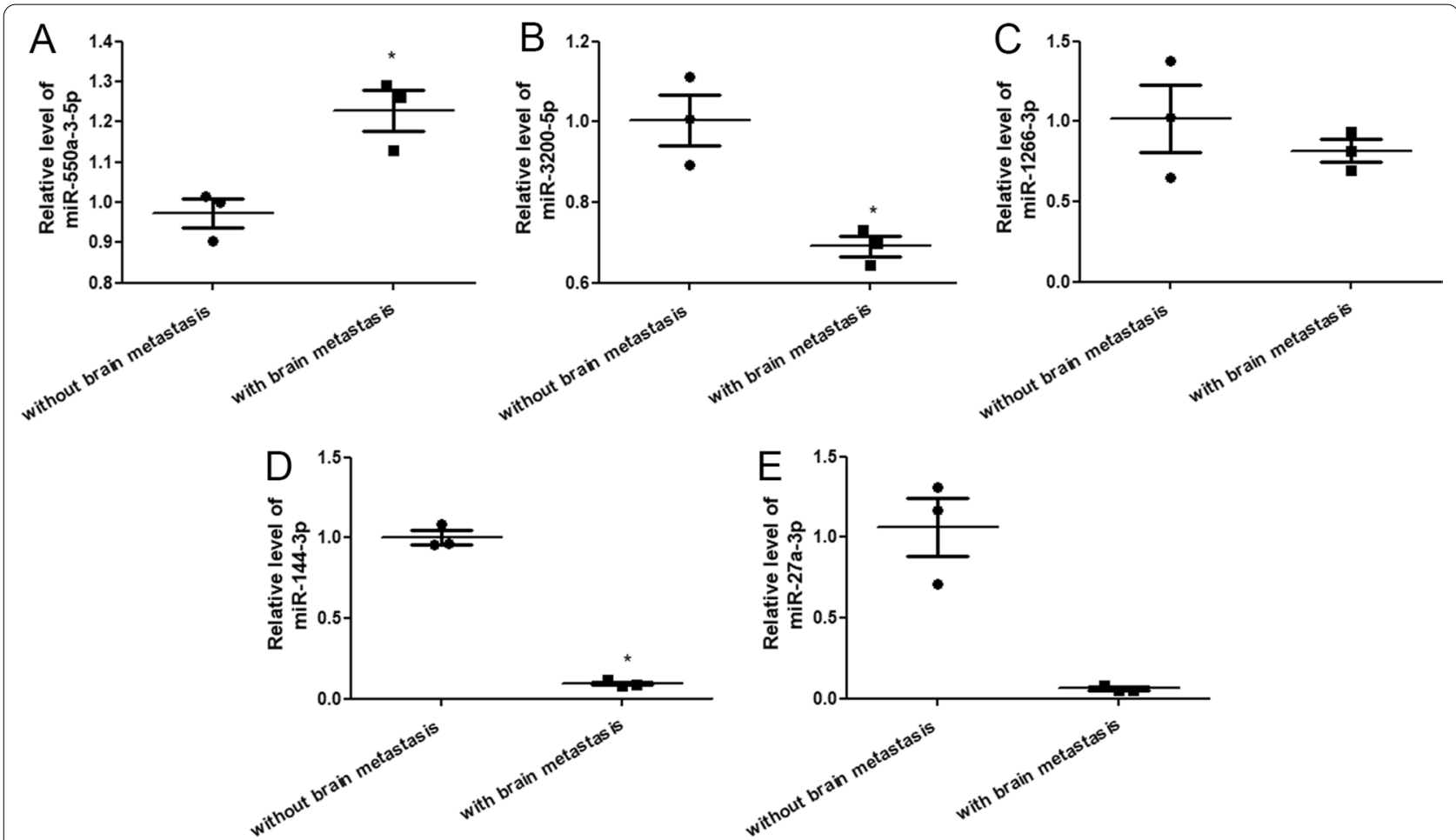

Fig. 3 Verification of sequencing data. The levels of miR-550a-3-5p (A), miR-3200-5p (B), miR-1226-3p (C), miR-144-3p (D) and miR-27a-3p (E) in exosomes isolated from plasma of lung cancer patients with or without brain metastasis. ${ }^{*} P<0.05$, compared with exosomes isolated from plasma of lung cancer patients without brain metastasis

with lung cancer with brain metastasis plasma-derived exosomes (higher miR-550a-3-5p levels) and 95D (high metastatic lung cancer cells)-derived exosomes (higher miR-550a-3-5p levels) was significantly lower than that of the control group $(P<0.05$; Fig. 5A). These results indicate that exosomes with higher miR-550a-3-5p levels can inhibit the viability of HBMECs.

As shown in Fig. 5B, no significant difference in cell viability was observed between the control and miRNA NC groups $(P>0.05)$. After cultured for $24 \mathrm{~h}$, cell viability was significantly decreased in the miR-550a3-5p mimics and exosomes groups compared with the control group $(P<0.05)$, while cell viability was significantly higher in the miR-550a-3-5p inhibitor group than in the miR-550a-3-5p mimics group $(P<0.05$; Fig. 5B). After culturing for $48 \mathrm{~h}, 72 \mathrm{~h}$ and $96 \mathrm{~h}$, miR550a-3-5p and exosomes significantly reduced cell viability $(P<0.05)$, whereas miR-550a-3-5p inhibitor significantly enhanced cell viability compared with the control $(P<0.05$; Fig. 5B). These results indicate that miR-550a-3-5p enrichment, similar with lung cancer with brain metastasis plasma-derived exosomes and high metastatic lung cancer cell-derived exosomes, could reduce the viability of HBMECs, while miR-550a3-5p inhibition had the opposite effect.
Cell migration was determined using the Transwell assay. There was no significant difference in cell migration between control and miRNA NC groups, or between miR-550a-3-5p mimics and exosome groups $(P>0.05$; Fig. 5C). After transfection with miR-550a-3-5p mimics and exosomes, the cell numbers were significantly decreased compared with the controls $(P<0.05)$; whereas the cell numbers in the miR-550a-3-5p inhibitor group was significantly higher than in the miR-550a-3-5p mimics group $(P<0.05$; Fig. $5 C)$. These results suggest that miR-550a-3-5p enrichment and high metastatic lung cancer cell-derived exosomes can inhibit the migration of HBMECs.

\section{Apoptosis and cell cycle analysis}

Flow cytometry was used to determine the effects of miR-550a-3-5p and lung cancer cell-derived exosomes on apoptosis and cell cycle of HBMECs. There was no significant difference in cell apoptosis between the control and miRNA NC groups $(P>0.05$; Fig. 6A). Compared with the control group, cell apoptosis was significantly increased in the miR-550a-3-5p mimics and cell-derived exosome groups $(P<0.05)$, but was markedly decreased in the miR-550a-3-5p inhibitor group $(P<0.05$; Fig. 6A). In addition, cell cycle analysis showed that the cells 

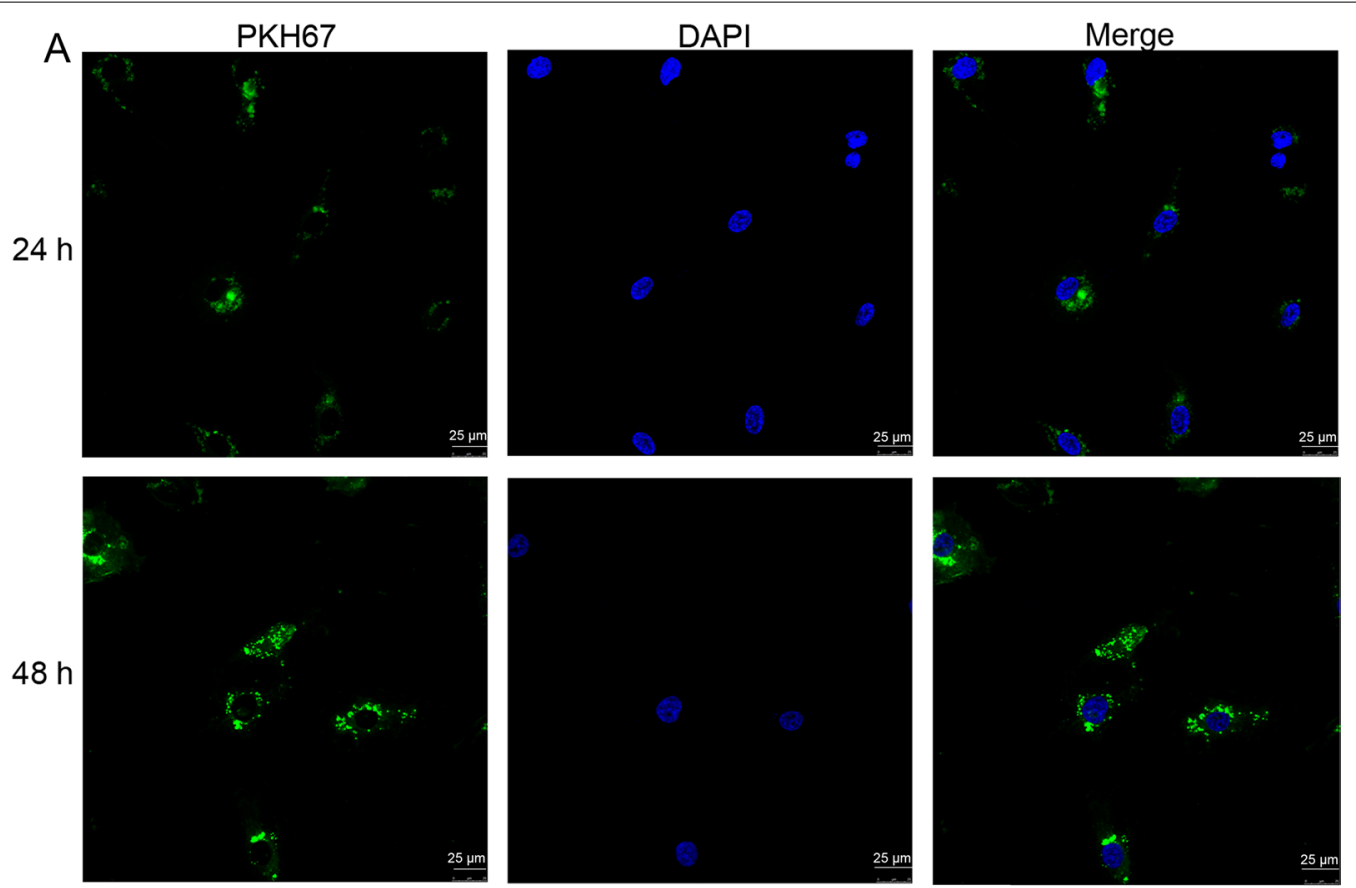

B

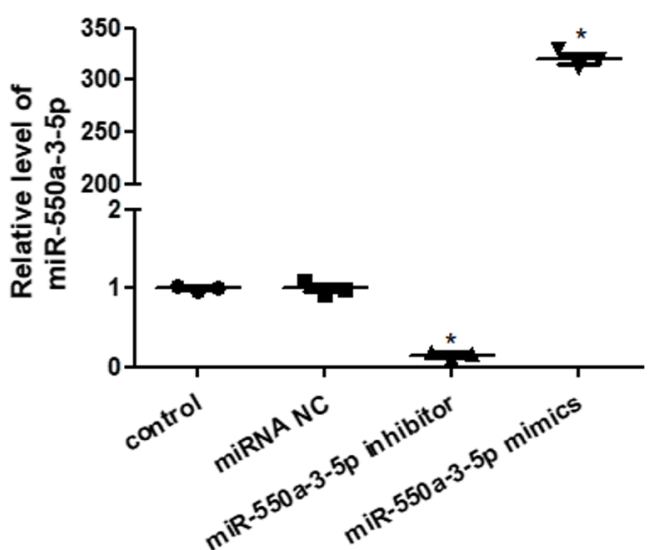

Fig. 4 Cellular uptake of lung cancer cell-derived exosomes and cell transfection efficiency analysis. A Cell-derived exosomes were labeled green by PKH67 and PKH67-labeled exosomes could be taken up by human brain microvascular epithelial cells (HBMECs) after co-culturing. B The relative levels of miR-550a-3-5p after transfection with miR-550a-3-5p inhibitor and mimics. ${ }^{*} P<0.05$, compared with the control group

transfected with miR-550a-3-5p mimics and cell-derived exosomes were significantly reduced during the G0/G1 phase compared with controls $(P<0.05)$, whereas the number of cells in the miR-550a-3-5p inhibitor group was notably higher than in the miR-550a-3-5p mimic group $(P<0.05$; Fig. 6B). During the S phase, miR-550a-3-5p mimics and cell-derived exosomes significantly increased the number of cells compared with controls $(P<0.05)$, and miR-550a-3-5p inhibitor significantly decreased the number of cells compared with the control and miR550a-3-5p mimics $(P<0.05$; Fig. 6B). No significant differences were observed in the $\mathrm{G} 2 / \mathrm{M}$ phase. These results indicate that miR-550a-3-5p enrichment, similar with high metastatic lung cancer cell-derived exosomes, could promote apoptosis of HBMECs and regulate cell distribution in the G0/G1 and S phases.

\section{Western blot assays}

The expression levels of cleaved-PARP, pRB, CDK6, YAP1, CTGF, and CYR61 proteins were measured using western blotting. The bands corresponding to the specific proteins are shown in Fig. 7A. No significant differences were observed in the expression of cleavedPARP, pRB, CDK6, YAP1, CTGF, and CYR61 proteins between control and miRNA NC groups, and between miR-550a-3-5p mimics and exosomes groups $(P>0.05$; 


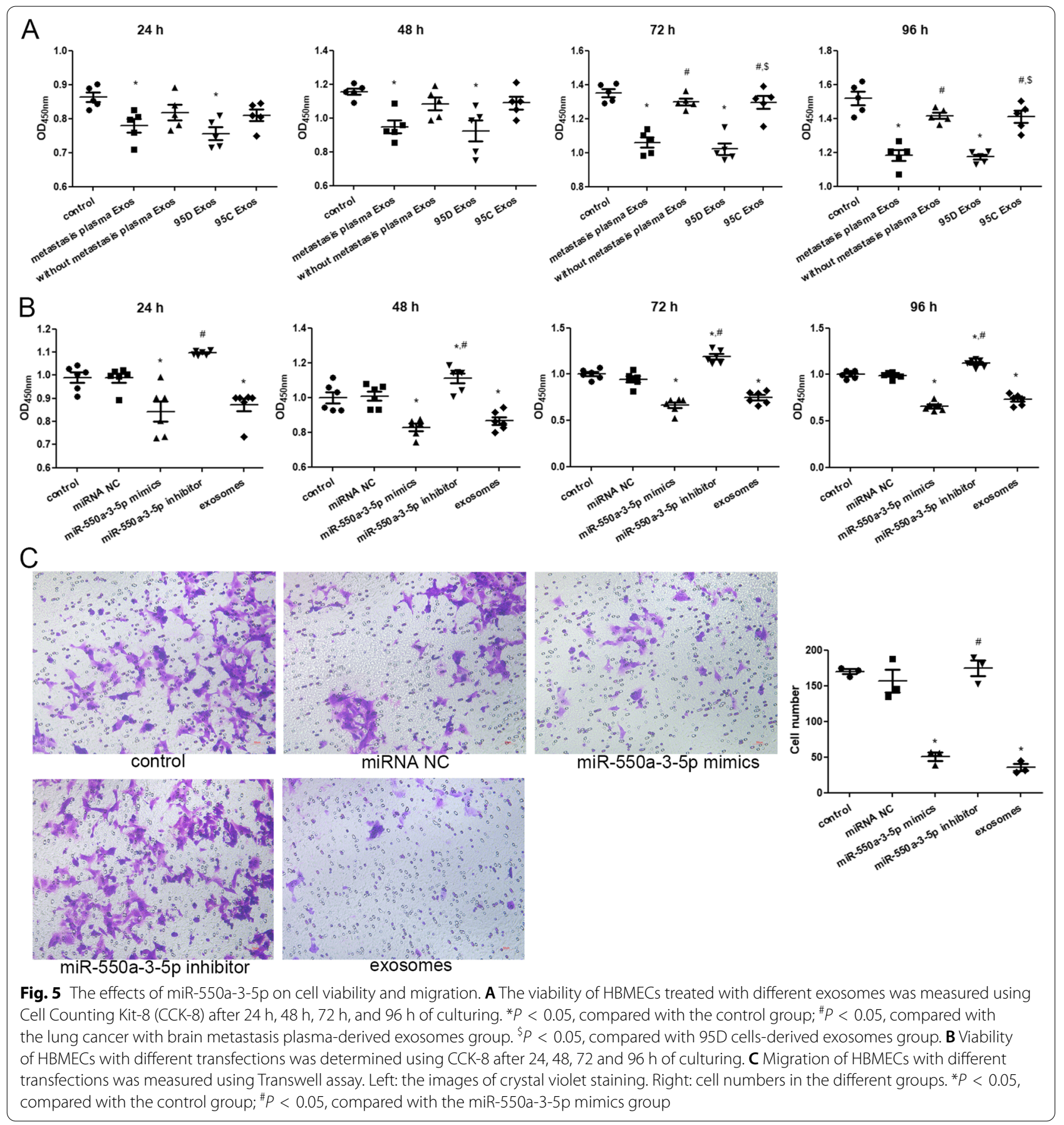

Fig. 7). Compared with the control group, the expression of cleaved-PARP was significantly upregulated in the miR-550a-3-5p mimic and exosome groups $(P<$ $0.05)$, but downregulated in the miR-550a-3-5p inhibitor group $(P<0.05$; Fig. 7A, B). However, the trend in the expression of $\mathrm{pRB}$ protein in the different groups was opposite to that of cleaved-PARP (Fig. 7A, C). The expression of CDK6, YAP1, CTGF, and CYR61 proteins was significantly lower in the miR-550a-3-5p mimics and exosomes groups $(P<0.05)$, but higher in the miR550a-a3-5p inhibitor group than in the control group $(P<0.05$; Fig. 7A, D-G). Additionally, miR-550a-3-5p inhibition significantly upregulated the expression of these proteins compared with the addition of miR550a-3-5p mimics $(P<0.05)$. 


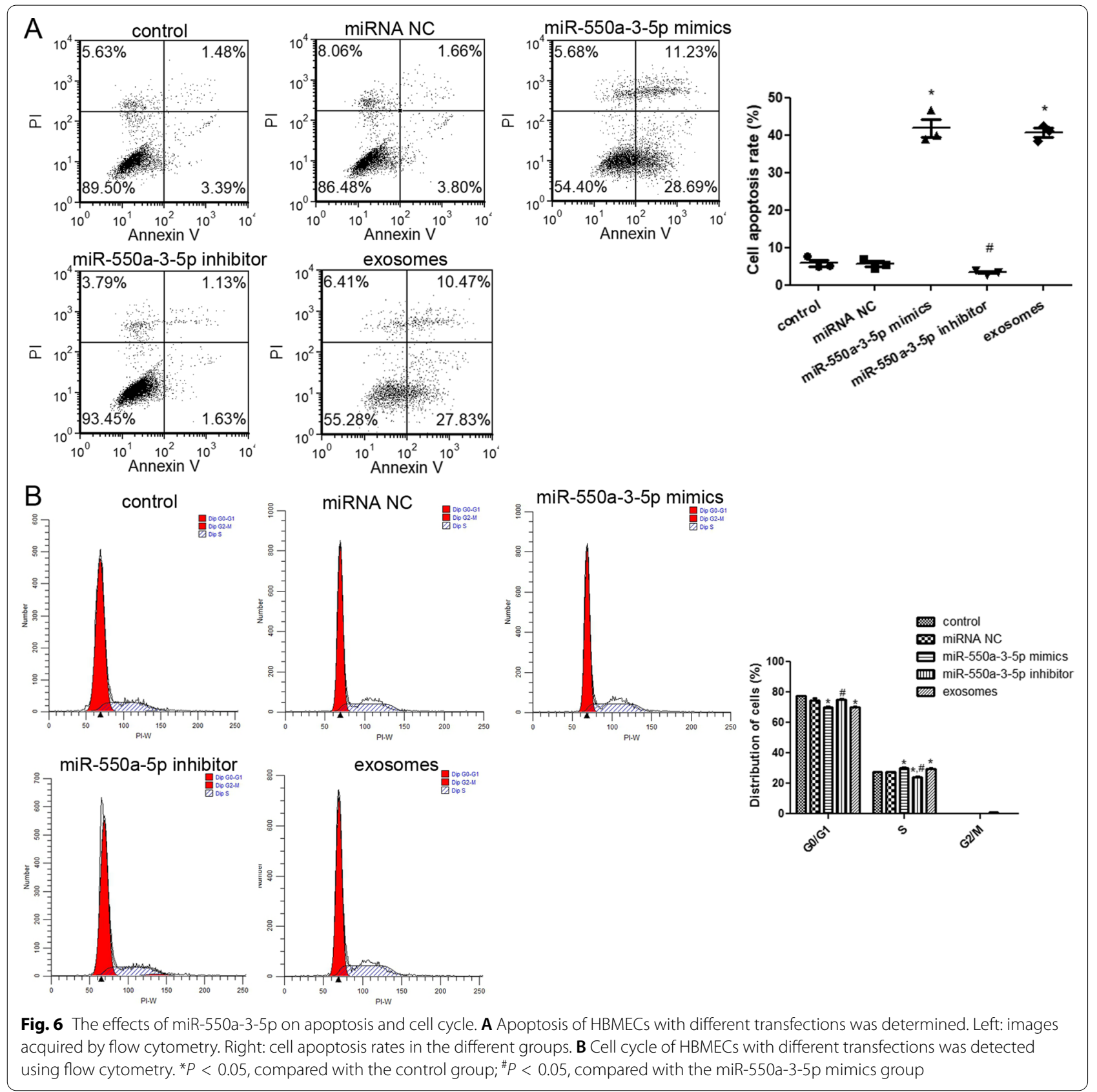

YAP1 directly binds with miR-550a-3-5p

YAP1 was predicted to be the target gene of miR-550a3-5p in lung cancer cell-derived exosomes, because the $3^{\prime}$-UTR of YAP1 contains the binding site for miR-550a3-5p (Fig. 8). To confirm this prediction, a dual-luciferase reporter gene assay was performed. No significant difference in relative luciferase activity was observed between NC mimics and miR-550a-3-5p mimics in the pGL3-basic plasmid $(P>0.05)$. However, relative luciferase activity was significantly decreased following
pGL3-YAP1 transfection with miR-550a-3-5p compared with pGL3-YAP1 transfection with NC mimics $(P<0.05$; Fig. 8). These results indicate that YAP1 directly binds to miR-550a-3-5p.

\section{Discussion}

Brain metastasis in patients with lung cancer is a major cause of poor prognosis, recurrence, and death [29]. However, there are few reports on the potential molecular mechanisms and therapeutic targets of lung cancer 


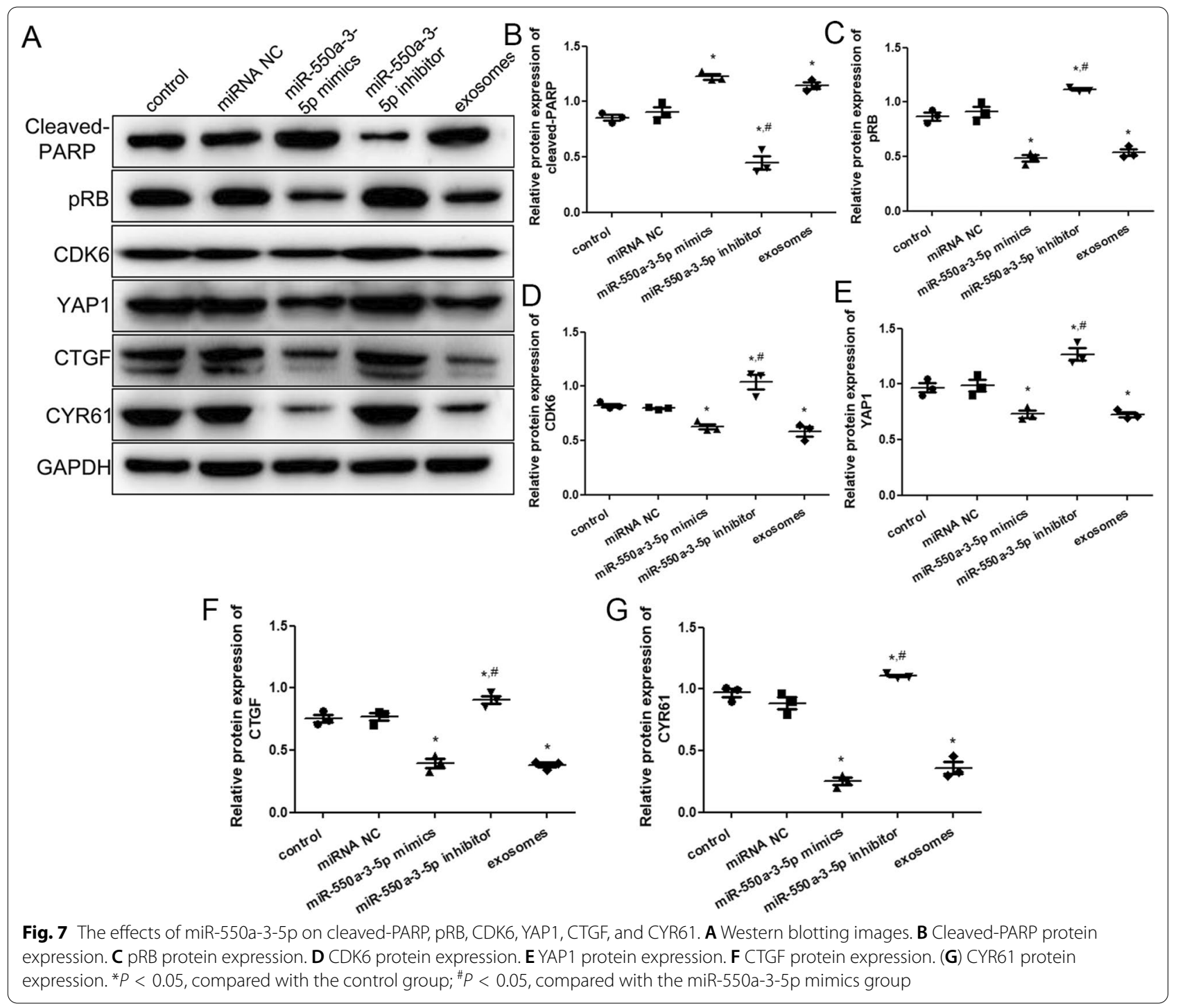

with brain metastasis. Our study identified 22 DE-miRNAs between the exosomes isolated from the plasma of lung cancer patients with or without brain metastasis. RT-qPCR showed that miR-550a-3-5p was significantly enriched in exosomes isolated from lung cancer patients with brain metastasis and miR-550a-3-5p was selected for further cellular experiments. Exosomes were then extracted from low or high metastatic lung cancer cells, and HBMECs were transfected with miRNA NC, miR550a-3-5p mimics, miR-550a-3-5p inhibitor, and high metastatic lung cancer cell-derived exosomes. It was found that miR-550a-3-5p enrichment, similar with high metastatic lung cancer cell-derived exosomes, inhibited the viability and migration of HBMECs, promoted their apoptosis, and regulated the cell cycle. Western blot analysis results showed that miR-550a-3-5p enrichment significantly upregulated the expression of cleaved-PARP and downregulated the expression of pRB, CDK6, YAP1, CTGF, and CYR61 proteins. Finally, dual-luciferase reporter gene assay indicated that YAP1 was miR-550a-3$5 p$ 's target gene. Our results identified the miRNAs associated with brain metastasis of lung cancer and indicate that miR-550a-3-5p and YAP1 may be novel potential targets for controlling brain metastasis.

Previous studies have shown that a variety of miRNAs have carcinogenic or tumor suppressive activity and play important roles in the metastasis and progression of lung cancer [30, 31]. In this study, 22 DE-miRNAs (10 upregulated and 12 downregulated) were identified and enriched in $44 \mathrm{BP}, 9 \mathrm{CC}$, and $13 \mathrm{MF}$, and several signaling pathways, including MAPK, chemokine, PPAR, and Wnt signaling pathways. The MAPK signaling pathway is involved in extensive cellular processes, including viability, proliferation, apoptosis, and differentiation [32]. 

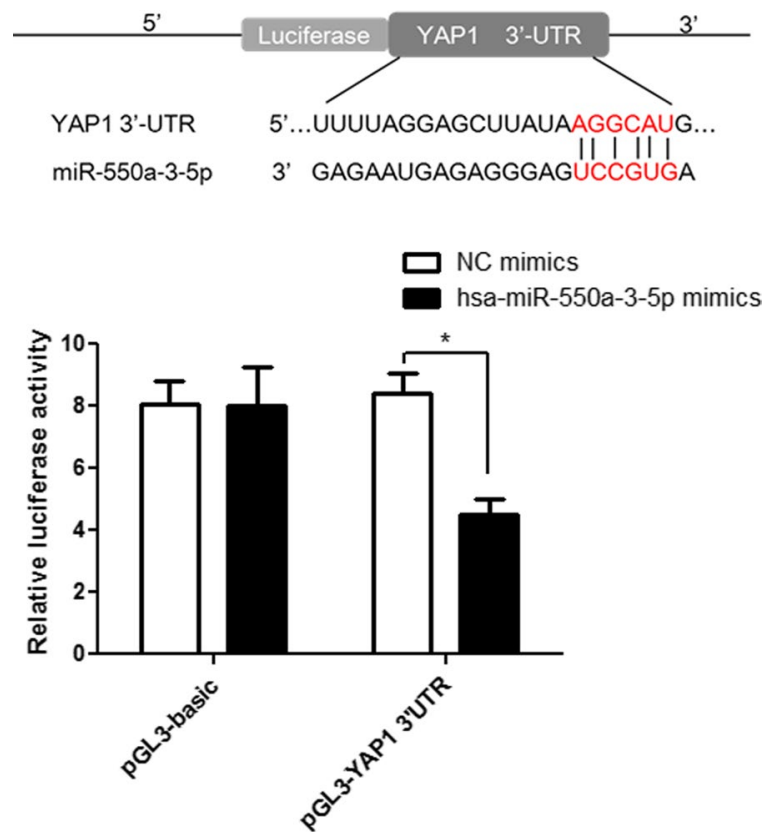

Fig. 8 Dual-luciferase reporter gene assay confirmed that YAP1 binds directly with miR-550a-3-5p

Zhang et al. [33] demonstrated that the activation of the MAPK signaling pathway is closely associated with the metastasis and invasion of hepatocellular carcinoma. The secretion and production of chemokines such as CCL2, CXCR1/2, CXCL12, CXCR4, and CXCL8 play critical roles in cancer development and subsequent metastasis [34-36]. Aldinucci and Casagrande [37] elaborated on the roles of CCL5 and CCR5 in cell proliferation and metastasis of gastric cancer, and their interaction in regulating immune and inflammatory responses. PPAR has three different subtypes (PPAR $\alpha, \operatorname{PPAR} \beta / \delta$, and PPAR $\gamma$ ) and has been shown to participate in the brain metastasis of cancer cells [38]. Additionally, the Wnt signaling pathway plays an essential role in maintaining homeostasis and regulating proliferation in various tissues [39]. Nguyen et al. [40] showed that the Wnt/TCF signaling pathway mediates the metastasis of lung adenocarcinoma through HOXB9 and LEF1. Based on the results of our study and those from previous studies, we hypothesize that these 10 upregulated and 12 downregulated DEmiRNAs, together with the MAPK, chemokine, PPAR, and Wnt signaling pathways, may be closely associated with brain metastasis of lung cancer. However, the roles of these pathways in brain metastasis of lung cancer need to be explored further.

Due to the higher level of miR-550a-3-5p in the exosomes isolated from the plasma of lung cancer patients with brain metastasis, miR-550a-3-5p was chosen for further cellular experiments. The results of these experiments showed that miR-550a-3-5p enrichment and high metastatic lung cancer cell-derived exosomes significantly suppressed HBMEC viability and migration, enhanced HBMEC apoptosis, decreased the number of cells during the G0/G1 phase, and increased the number of cells during the $\mathrm{S}$ phase, whereas miR550a-3-5p inhibition had the opposite effects. Wei et al. [41] found that miR-330-3p overexpression promoted the proliferation, migration, and invasion of non-small cell lung cancer (NSCLC) in vitro and facilitated the occurrence of NSCLC tumors in vivo; thus, miR-330-3p may be a biomarker of NSCLC with metastasis. Another study showed that silencing miR-202-3p could destroy the interendothelial junction and enhance the migration of breast cancer cells by upregulating MMP-1, suggesting that miR-202-3p/MMP-1 may be used to predict the metastasis of breast cancer [42]. Together with our results, it can be inferred that exosomal miR-550a-3-5p, as a new biomarker, may affect brain metastasis of lung cancer by regulating the viability, migration, apoptosis, and cycle of HBMECs.

Further, to investigate the underlying molecular mechanisms of miR-550a-3-5p affecting brain metastasis, the expression of cleaved-PARP, pRB, CDK6, YAP1, CTGF, and CYR61 proteins was determined using western blotting. High levels of both miR-550a3-5p and high metastatic lung cancer cell-derived exosomes markedly upregulated cleaved-PARP protein expression while downregulating pRB, CDK6, YAP1, CTGF, and CYR61 protein expression. PARP plays a key role in detecting genomic damage signals, DNA repair and replication, transcription and regulation of post-transcriptional gene expression, cell growth regulation, and inflammation [43]. PARP is also involved in a variety of pathological processes, including carcinogenesis, regulation of oncogenic transcription factors, and direct or mediated interactions with oncogenes [44]. Zhang et al. [45] showed that lncRNA MALAT1 knockdown could promote the apoptosis of chondrocytes by upregulating cleaved-PARP protein expression, thereby alleviating the progression of osteoarthritis. Previous studies have reported that $\mathrm{pRB}$ plays an important role in regulating the expression of target genes that induce cell cycle arrest, apoptosis, and differentiation, and that its dysfunction can contribute to disordered cell growth and chromosomal instability, which are hallmarks of cancer cells $[46,47]$. CDK6, as a cell cycle-dependent kinase and a transcriptional regulator, has been reported to lead to disordered cell cycle regulation and uncontrolled cell proliferation, and plays a crucial role in promoting cancer occurrence and development [48, 49]. Zhu 
et al. [50] showed that let-7c overexpression induced apoptosis in human hepatocellular carcinoma cells and arrested the G1 cell cycle by downregulating the levels of Cyclin D1, CDK6, E2F2, and pRB proteins. CTGF, a member of the $\mathrm{CCN}$ stromal cell protein family, participates in many BP, including inducing the expression of inflammatory cytokines, promoting cell adhesion, and regulating tissue remodeling and fibrosis [51, 52]. A previous study indicated that CTGF expression in high bone metastatic prostate cancer cells was 1.9 times higher than in low bone metastatic prostate cancer cells, and the increased CTGF expression did not affect tumor cell proliferation but significantly expanded the tumor area at the site of bone metastasis [53]. CYR61, a secreted matricellular protein, has been shown to accelerate tumor growth, angiogenesis, cell invasion, and metastasis in different solid tumors [54, 55]. Habel et al. [56] demonstrated that CYR61 levels control the expression of markers associated with the process of epithelial-mesenchymal transition, thus inducing tumor cell migration and invasion in osteosarcoma. These findings, combined with our results, support the hypothesis that exosomal miR-550a-3-5p may regulate cell viability, apoptosis, cell cycle, and migration of HBMECs by mediating cleaved-PARP, pRB, CDK6, CTGF, and CYR61 expression, consequently influencing brain metastasis of lung cancer.

In addition, YAP1, as the primary effector of the Hippo pathway, plays an essential role in a variety of biological functions, including cell proliferation, differentiation, and intercellular contact inhibition [57, 58]. Previous studies have shown that abnormal expression of YAP1 occurs in many malignant tumors [58, 59]. Our study found that YAP1 protein expression was significantly downregulated after transfection with miR-550a-3-5p mimics and high metastatic lung cancer cell-derived exosomes, whereas it was significantly upregulated after inhibition of miR-550a-3-5p. Dual-luciferase reporter gene assay results showed that YAP1 directly binds to miR-550a-3-5p. Sun et al. [60] reported that YAP1 was highly expressed in colorectal carcinoma (CRC) tissues, and in vivo and in vitro experiments showed that YAP1 could enhance the proliferation, migration, and invasion of CRC cells. Another study confirmed the negative correlation between miR-550a-3-5p and YAP1 in colon cancer tissues, and showed that miR-550a-3-5p could repress tumor cell proliferation, metastasis, and sphere formation by directly inhibiting YAP1 and its oncogenic pathway in various cancer cell types [27]. Taken together, exosomal miR-550a-3-5p may control the progression of lung cancer with brain metastasis by targeting YAP1 expression.

\section{Conclusions}

In conclusion, through exosome sequencing, we identified 22 DE-miRNAs, and showed that the MAPK, chemokine, PPAR, and Wnt signaling pathways may be associated with brain metastasis of lung cancer. Additionally, YAP1 was identified as the target gene of exosomal miR-550a-3-5p, and miR-550a-3-5p may regulate the growth and migration of HBMECs by mediating YAP1, cleaved-PARP, pRB, CDK6, CTGF, and CYR61 protein expression, thus controlling brain metastasis of lung cancer. However, further experiments using additional clinical samples need to be carried out to verify these results. Our findings will help to improve our understanding of the progression of brain metastasis and provide a basis for using miR-550a-3-5p and YAP1 as potential targets for controlling brain metastasis of lung cancer.

\section{Supplementary Information}

The online version contains supplementary material available at https://doi. org/10.1186/s12935-021-02197-z.

Additional file 1: Figure S1. Functional analyses of differentially expressed differentially expressed miRNAs (DE-miRNAs). (A) Gene Ontology terms analysis of DE-miRNAs. (B) Kyoto Encyclopedia of Genes and Genomes pathways enrichment of DE-miRNAs.

\section{Acknowledgements}

Not applicable.

\section{Authors' contributions}

LW, GW, CZ, and QL designed the experiments. LW, GW, CY, YZ, and YC performed the experiments and analyzed the data. $L W$ and $Q L$ obtained the funding and supervised the study. LW and GW drafted the paper. CZ and QL revised the manuscript. All authors read and approved the final manuscript.

\section{Funding}

This work was supported by the Pudong new area science and technology development fund (PKJ2018-Y04), Health Special Project of Pudong Health Bureau of Shanghai (PW2020E-5), the National Natural Science Foundation of China (PKJ2020-Y44), and Shanghai Municipal Key Specialty Construction Fund of Shanghai Municipal Health Bureau (81773266).

\section{Availability of data and materials}

The dataset used and/or analyzed during the current study are available from the corresponding author on reasonable request.

\section{Declarations}

\section{Ethics approval and consent to participate}

All participants provided informed consent for inclusion in the study. The study was conducted in accordance with the Declaration of Helsinki and the protocol was approved by the Ethics Committee of Shanghai East Hospital affiliated with Tongji University [(2020) Research on No.135].

\section{Consent for publication}

Not applicable.

\section{Competing interests}

The authors declare that the research was conducted in the absence of any commercial or financial relationships that could be construed as a potential competing interests. 


\section{Author details}

${ }^{1}$ Department of Neurosurgery, East Hospital, Tongji University School of Medicine, 150 Jimo Road, Shanghai 200120, China. ${ }^{2}$ Research Center for Translational Medicine, East Hospital, Tongji University School of Medicine, 150 Jimo Road, Shanghai 200120, China. ${ }^{3}$ Department of Cardiothoracic Surgery, East Hospital, Tongji University School of Medicine, 150 Jimo Road, Shanghai 200120, China.

Received: 21 May 2021 Accepted: 6 September 2021 Published online: 16 September 2021

\section{References}

1. Yun L, Liqun W, Shuqi Y, Chunxiao W, Liming L, Wei Y. Acupuncture for infertile women without undergoing assisted reproductive techniques (ART): a systematic review and meta-analysis. Medicine. 2019;98(29): e16463. https://doi.org/10.1097/MD.0000000000016463.

2. Liu JK, Liu HF, Ding Y, Gao GD. Predictive value of microRNA let-7a expression for efficacy and prognosis of radiotherapy in patients with lung cancer brain metastasis: a case-control study. Medicine. 2018;97(44): e12847. https://doi.org/10.1097/MD.0000000000012847.

3. Nieder C, Bremnes RM, Andratschke NH. Prognostic scores in patients with brain metastases from non-small cell lung cancer. J Thorac Oncol. 2009;4(11):1337-41. https://doi.org/10.1097/JTO.0b013e3181b6b6f4.

4. Popper HH. Progression and metastasis of lung cancer. Cancer Metastasis Rev. 2016:35(1):75-91. https://doi.org/10.1007/s10555-016-9618-0.

5. Schouten $\sqcup$, Rutten J, Huveneers HA, Twijnstra A. Incidence of brain metastases in a cohort of patients with carcinoma of the breast, colon, kidney, and lung and melanoma. Cancer. 2002;94(10):2698-705. https:// doi.org/10.1002/cncr.10541.

6. Alberg AJ, Ford JG, Samet JM, American College of Chest P. Epidemiology of lung cancer: ACCP evidence-based clinical practice guidelines. Chest. 2007;132(3 Suppl):29S-55S. https://doi.org/10.1378/chest.07-1347.

7. Arvold ND, Lee EQ, Mehta MP, Margolin K, Alexander BM, Lin NU, Anders CK, Soffietti R, Camidge DR, Vogelbaum MA, Dunn IF, Wen PY. Updates in the management of brain metastases. Neuro Oncol. 2016;18(8):1043-65. https://doi.org/10.1093/neuonc/now127.

8. Meldolesi J. Exosomes and ectosomes in intercellular communication. Curr Biol. 2018;28(8):R435-44. https://doi.org/10.1016/j.cub.2018.01.059.

9. Kalluri R, LeBleu VS. The biology, function, and biomedical applications of exosomes. Science. 2020. https://doi.org/10.1126/science.aau6977.

10. Hood JL, San RS, Wickline SA. Exosomes released by melanoma cells prepare sentinel lymph nodes for tumor metastasis. Cancer Res. 2011;71(11):3792-801. https://doi.org/10.1158/0008-5472.CAN-10-4455.

11. Zhuang G, Wu X, Jiang Z, Kasman I, Yao J, Guan Y, Oeh J, Modrusan Z, Bais C, Sampath D, Ferrara N. Tumour-secreted miR-9 promotes endothelial cell migration and angiogenesis by activating the JAK-STAT pathway. EMBO J. 2012;31(17):3513-23. https://doi.org/10.1038/emboj.2012.183.

12. Chow A, Zhou W, Liu L, Fong MY, Champer J, Van Haute D, Chin AR, Ren X, Gugiu BG, Meng Z, Huang W, Ngo V, Kortylewski M, Wang SE. Macrophage immunomodulation by breast cancer-derived exosomes requires Toll-like receptor 2-mediated activation of NF-kappaB. Sci Rep. 2014;4:5750. https://doi.org/10.1038/srep05750.

13. Ham S, Lima LG, Chai EPZ, Muller A, Lobb RJ, Krumeich S, Wen SW, Wieg mans AP, Moller A. Breast cancer-derived exosomes alter macrophage polarization via gp130/STAT3 signaling. Front Immunol. 2018;9:871. https://doi.org/10.3389/fimmu.2018.00871.

14. Sato J, Shimomura A, Kawauchi J, Matsuzaki J, Yamamoto Y, Takizawa S, Sakamoto H, Ohno M, Narita Y, Ochiya T, Tamura K. Brain metastasisrelated microRNAs in patients with advanced breast cancer. PLoS ONE. 2019;14(10): e0221538. https://doi.org/10.1371/journal.pone.0221538.

15. Alsidawi S, Malek E, Driscoll JJ. MicroRNAs in brain metastases: potential role as diagnostics and therapeutics. Int J Mol Sci. 2014;15(6):10508-26. https://doi.org/10.3390/ijms150610508.

16. Bartel DP. MicroRNAs: target recognition and regulatory functions. Cell. 2009;136(2):215-33. https://doi.org/10.1016/j.cell.2009.01.002.

17. Alipoor SD, Adcock IM, Garssen J, Mortaz E, Varahram M, Mirsaeidi M, Velayati A. The roles of miRNAs as potential biomarkers in lung diseases.
Eur J Pharmacol. 2016;791:395-404. https://doi.org/10.1016/j.ejphar.2016. 09.015.

18. Zeng Z, Li Y, Pan Y, Lan X, Song F, Sun J, Zhou K, Liu X, Ren X, Wang F, Hu J, Zhu X, Yang W, Liao W, Li G, Ding Y, Liang L. Cancer-derived exosomal miR-25-3p promotes pre-metastatic niche formation by inducing vascular permeability and angiogenesis. Nat Commun. 2018;9(1):5395. https:// doi.org/10.1038/s41467-018-07810-w.

19. Dou D, Ren X, Han M, Xu X, Ge X, Gu Y, Wang X. Cancer-associated fibroblasts-derived exosomes suppress immune cell function in breast cancer via the miR-92/PD-L1 pathway. Front Immunol. 2020;11:2026. https://doi.org/10.3389/fimmu.2020.02026.

20. Zhu Q, Li Q, Niu X, Zhang G, Ling X, Zhang J, Wang Y, Deng Z. Extracellular vesicles secreted by human urine-derived stem cells promote ischemia repair in a mouse model of hind-limb ischemia. Cell Physiol Biochem. 2018;47(3):1181-92. https://doi.org/10.1159/000490214.

21. Soares Martins T, Catita J, Martins Rosa I, da Cruz-e-Silva AB, Henriques AG. Exosome isolation from distinct biofluids using precipitation and column-based approaches. PLoS ONE. 2018;13(6): e0198820. https://doi. org/10.1371/journal.pone.0198820.

22. Yin J, Zeng A, Zhang Z, Shi Z, Yan W, You Y. Exosomal transfer of miR-1238 contributes to temozolomide-resistance in glioblastoma. EBioMedicine. 2019;42:238-51. https://doi.org/10.1016/j.ebiom.2019.03.016.

23. Zhang L, Sullivan PS, Goodman JC, Gunaratne PH, Marchetti D. MicroRNA- 1258 suppresses breast cancer brain metastasis by targeting heparanase. Cancer Res. 2011;71(3):645-54. https://doi.org/10.1158/0008-5472. CAN-10-1910.

24. Yang C, Liu X, Zhao K, Zhu Y, Hu B, Zhou Y, Wang M, Wu Y, Zhang C, Xu J, Ning Y, Zou D. miRNA-21 promotes osteogenesis via the PTEN/PI3K Akt/HIF-1alpha pathway and enhances bone regeneration in critical size defects. Stem Cell Res Ther. 2019;10(1):65. https://doi.org/10.1186/ s13287-019-1168-2.

25. Xu G, Ao R, Zhi Z, Jia J, Yu B. miR-21 and miR-19b delivered by hMSCderived $E V s$ regulate the apoptosis and differentiation of neurons in patients with spinal cord injury. J Cell Physiol. 2019;234(7):10205-17. https://doi.org/10.1002/jcp.27690.

26. Wan L, Yuan X, Liu M, Xue B. miRNA-223-3p regulates NLRP3 to promote apoptosis and inhibit proliferation of hep3B cells. Exp Ther Med. 2018;15(3):2429-35. https://doi.org/10.3892/etm.2017.5667.

27. Choe MH, Yoon Y, Kim J, Hwang SG, Han YH, Kim JS. miR-550a-3-5p acts as a tumor suppressor and reverses BRAF inhibitor resistance through the direct targeting of YAP. Cell Death Dis. 2018;9(6):640. https://doi.org/10. 1038/s41419-018-0698-3.

28. Park ST, Kim J. Trends in next-generation sequencing and a new era for whole genome sequencing. Int Neurourol J. 2016;20(Suppl 2):S76-83. https://doi.org/10.5213/inj.1632742.371.

29. Masuda C, Sugimoto M, Wakita D, Monnai M, Ishimaru C, Nakamura R, Kinoshita M, Yorozu K, Kurasawa M, Kondoh O, Yamamoto K. Bevacizumab suppresses the growth of established non-small-cell lung cancer brain metastases in a hematogenous brain metastasis model. Clin Exp Metastasis. 2020;37(1):199-207. https://doi.org/10.1007/s10585-019-10008-z.

30. Uddin A, Chakraborty S. Role of miRNAs in lung cancer. J Cell Physiol. 2018. https://doi.org/10.1002/jcp.26607.

31. Wang J, Raimondo M, Guha S, Chen J, Diao L, Dong X, Wallace MB, Killary AM, Frazier ML, Woodward TA, Wang J, Sen S. Circulating microRNAs in pancreatic juice as candidate biomarkers of pancreatic cancer. J Cancer. 2014;5(8):696-705. https://doi.org/10.7150/jca.10094.

32. Masliah-Planchon J, Garinet S, Pasmant E. RAS-MAPK pathway epigenetic activation in cancer: miRNAs in action. Oncotarget. 2016;7(25):38892-907. https://doi.org/10.18632/oncotarget.6476.

33. Zhang QY, Men CJ, Ding XW. Upregulation of microRNA-140-3p inhibits epithelial-mesenchymal transition, invasion, and metastasis of hepatocellular carcinoma through inactivation of the MAPK signaling pathway by targeting GRN. J Cell Biochem. 2019;120(9):14885-98. https://doi.org/10. 1002/jcb.28750.

34. Lim SY, Yuzhalin AE, Gordon-Weeks AN, Muschel RJ. Targeting the CCL2CCR2 signaling axis in cancer metastasis. Oncotarget. 2016;7(19):28697710. https://doi.org/10.18632/oncotarget.7376.

35. Teicher BA, Fricker SP. CXCL12 (SDF-1)/CXCR4 pathway in cancer. Clin Cancer Res. 2010;16(11):2927-31. https://doi.org/10.1158/1078-0432. CCR-09-2329. 
36. Nebbioso A, Benedetti R, Conte M, Carafa V, De Bellis F, Shaik J, Matarese F, Della Ventura B, Gesuele F, Velotta R, Martens JHA, Stunnenberg HG, Altucci C, Altucci L. Time-resolved analysis of DNA-protein interactions in living cells by UV laser pulses. Sci Rep. 2017;7(1):11725. https://doi.org/10. 1038/s41598-017-12010-5.

37. Aldinucci D, Casagrande N. Inhibition of the CCL5/CCR5 axis against the progression of gastric cancer. Int J Mol Sci. 2018. https://doi.org/10.3390/ ijms19051477.

38. Zou Y, Watters A, Cheng N, Perry CE, Xu K, Alicea GM, Parris JLD, Baraban E, Ray P, Nayak A, Xu X, Herlyn M, Murphy ME, Weeraratna AT, Schug ZT, Chen Q. Polyunsaturated fatty acids from astrocytes activate PPARgamma signaling in cancer cells to promote brain metastasis. Cancer Discov. 2019:9(12):1720-35. https://doi.org/10.1158/2159-8290.CD-19-0270.

39. Takahashi-Yanaga F, Sasaguri T. The Wnt/beta-catenin signaling pathway as a target in drug discovery. J Pharmacol Sci. 2007;104(4):293-302. https://doi.org/10.1254/jphs.cr0070024.

40. Nguyen DX, Chiang AC, Zhang XH, Kim JY, Kris MG, Ladanyi M, Gerald WL, Massague J. WNT/TCF signaling through LEF1 and HOXB9 mediates lung adenocarcinoma metastasis. Cell. 2009;138(1):51-62. https://doi.org/10. 1016/j.cell.2009.04.030.

41. Wei C, Zhang R, Cai Q, Gao X, Tong F, Dong J, Hu Y, Wu G, Dong X. MicroRNA-330-3p promotes brain metastasis and epithelial-mesenchymal transition via GRIA3 in non-small cell lung cancer. Aging. 2019;11(17):6734-61. https://doi.org/10.18632/aging.102201.

42. Harati R, Hafezi S, Mabondzo A, Tili A. Silencing miR-202-3p increases MMP-1 and promotes a brain invasive phenotype in metastatic breast cancer cells. PLoS ONE. 2020;15(10): e0239292. https://doi.org/10.1371/ journal.pone.0239292.

43. Lai SW, Bamodu OA, Chen JH, Wu AT, Lee WH, Chao TY, Yeh CT. Targeted PARP inhibition combined with FGFR1 blockade is synthetically lethal to malignant cells in patients with pancreatic cancer. Cells. 2020. https://doi. org/10.3390/cells9040911.

44. Rajawat J, Shukla N, Mishra DP. Therapeutic targeting of poly(ADP-Ribose) polymerase-1 (PARP1) in cancer: current developments, therapeutic strategies, and future opportunities. Med Res Rev. 2017;37(6):1461-91. https:// doi.org/10.1002/med.21442.

45. Zhang $Y$, Wang $F$, Chen $G$, He R, Yang L. LncRNA MALAT1 promotes osteoarthritis by modulating miR-150-5p/AKT3 axis. Cell Biosci. 2019;9:54. https://doi.org/10.1186/s13578-019-0302-2.

46. Uchida C. Roles of pRB in the regulation of nucleosome and chromatin structures. Biomed Res Int. 2016;2016:5959721. https://doi.org/10.1155/ 2016/5959721.

47. Takahashi Y, Rayman JB, Dynlacht BD. Analysis of promoter binding by the E2F and pRB families in vivo: distinct E2F proteins mediate activation and repression. Genes Dev. 2000;14(7):804-16.

48. Malumbres M, Barbacid M. Cell cycle, CDKs and cancer: a changing paradigm. Nat Rev Cancer. 2009;9(3):153-66. https://doi.org/10.1038/nrc2602.

49. Nebenfuehr S, Kollmann K, SexI V. The role of CDK6 in cancer. Int J Cancer. 2020;147(11):2988-95. https://doi.org/10.1002/ijc.33054.
50. Zhu X, Wu L, Yao J, Jiang H, Wang Q, Yang Z, Wu F. MicroRNA let-7c inhibits cell proliferation and induces cell cycle arrest by targeting CDC25A in human hepatocellular carcinoma. PLoS ONE. 2015;10(4): e0124266. https://doi.org/10.1371/journal.pone.0124266.

51. Toda N, Mukoyama M, Yanagita M, Yokoi H. CTGF in kidney fibrosis and glomerulonephritis. Inflamm Regen. 2018;38:14. https://doi.org/10.1186/ s41232-018-0070-0.

52. Lipson KE, Wong C, Teng Y, Spong S. CTGF is a central mediator of tissue remodeling and fibrosis and its inhibition can reverse the process of fibrosis. Fibrogenesis Tissue Repair. 2012;5(Suppl 1):S24. https://doi.org/ 10.1186/1755-1536-5-S1-S24.

53. Zhang S, Li B, Tang W, Ni L, Ma H, Lu M, Meng Q. Effects of connective tissue growth factor on prostate cancer bone metastasis and osteoblast differentiation. Oncol Lett. 2018;16(2):2305-11. https://doi.org/10.3892/ol. 2018.8960.

54. Jeong D, Heo S, Sung Ahn T, Lee S, Park S, Kim H, Park D, Byung Bae S, Lee SS, Soo Lee M, Kim CJ, Jun Baek M. Cyr61 expression is associated with prognosis in patients with colorectal cancer. BMC Cancer. 2014;14:164. https://doi.org/10.1186/1471-2407-14-164.

55. Sun ZJ, Wang Y, Cai Z, Chen PP, Tong XJ, Xie D. Involvement of Cyr61 in growth, migration, and metastasis of prostate cancer cells. Br J Cancer. 2008;99(10):1656-67. https://doi.org/10.1038/sj.bjc.6604712.

56. Habel N, Stefanovska B, Carene D, Patino-Garcia A, Lecanda F, Fromigue O. CYR61 triggers osteosarcoma metastatic spreading via an IGF1Rbetadependent EMT-like process. BMC Cancer. 2019;19(1):62. https://doi.org/ 10.1186/s12885-019-5282-4.

57. Zhao B, Tumaneng K, Guan KL. The Hippo pathway in organ size control, tissue regeneration and stem cell self-renewal. Nat Cell Biol. 2011;13(8):877-83. https://doi.org/10.1038/ncb2303.

58. Yu FX, Zhao B, Guan KL. Hippo pathway in organ size control, tissue homeostasis, and cancer. Cell. 2015;163(4):811-28. https://doi.org/10. 1016/j.cell.2015.10.044.

59. Ou C, Sun Z, He X, Li X, Fan S, Zheng X, Peng Q, Li G, Li X, Ma J. Targeting YAP1/LINC00152/FSCN1 signaling axis prevents the progression of colorectal cancer. Adv Sci. 2020;7(3):1901380. https://doi.org/10.1002/advs. 201901380.

60. Sun Z, Ou C, Liu J, Chen C, Zhou Q, Yang S, Li G, Wang G, Song J, Li Z, Zhang Z, Yuan W, Li X. YAP1-induced MALAT1 promotes epithelialmesenchymal transition and angiogenesis by sponging miR-126-5p in colorectal cancer. Oncogene. 2019;38(14):2627-44. https://doi.org/10. 1038/s41388-018-0628-y.

\section{Publisher's Note}

Springer Nature remains neutral with regard to jurisdictional claims in published maps and institutional affiliations.
Ready to submit your research? Choose BMC and benefit from:

- fast, convenient online submission

- thorough peer review by experienced researchers in your field

- rapid publication on acceptance

- support for research data, including large and complex data types

- gold Open Access which fosters wider collaboration and increased citations

- maximum visibility for your research: over $100 \mathrm{M}$ website views per year

At BMC, research is always in progress.

Learn more biomedcentral.com/submissions 